\title{
Promotion of prostatic metastatic migration towards human bone marrow stoma by Omega 6 and its inhibition by Omega 3 PUFAs
}

\author{
MD Brown*,1, CA Hart', E Gazi', S Bagley² and NW Clarke 1,3,4 \\ 'ProMPT Genito Urinary Cancer Research Group, Cancer Research UK Paterson Institute, Christie Hospital NHS Trust, Wilmslow Road, Manchester M20 \\ 4BX, UK: ${ }^{2}$ Advanced Imaging Facility, Cancer Research UK Paterson Institute, Christie Hospital NHS Trust, Wilmslow Road, Manchester M20 4BX, UK; \\ ${ }^{3}$ Department of Urology, Christie Hospital NHS Trust, Wilmslow Road, Manchester M20 4BX, UK; ${ }^{4}$ Department of Urology, Salford Royal Hospital \\ NHST, Eccles Old Road, Salford, M6 8HD, UK
}

Epidemiological studies have shown not only a relationship between the intake of dietary lipids and an increased risk of developing metastatic prostate cancer, but also the type of lipid intake that influences the risk of metastatic prostate cancer. The Omega- 6 polyunsaturated fatty acid, Arachidonic acid, has been shown to enhance the proliferation of malignant prostate epithelial cells and increase the risk of advanced prostate cancer. However, its role in potentiating the migration of cancer cells is unknown. Here we show that arachidonic acid at concentrations $\leqslant 5 \mu \mathrm{M}$ is a potent stimulator of malignant epithelial cellular invasion, which is able to restore invasion toward hydrocortisone-deprived adipocyte-free human bone marrow stroma completely. This observed invasion is mediated by the arachidonic acid metabolite prostaglandin $E_{2}$ and is inhibited by the Omega- 3 poly-unsaturated fatty acids eicosapentaenoic acid and docosahexaenoic acid at a ratio of I:2 Omega-3: Omega-6, and by the COX-2 inhibitor NS-398. These results identify a mechanism by which arachidonic acid may potentiate the risk of metastatic migration and secondary implantation in vivo, a risk which can be reduced with the uptake of Omega-3 poly-unsaturated fatty acids.

British Journal of Cancer (2006) 94, 842-853. doi:I0.I038/sj.bjc.6603030 www.bjcancer.com

Published online 7 March 2006

(c) 2006 Cancer Research UK

Keywords: prostate cancer; arachidonic acid; metastasis; bone marrow; Omega 6; Omega 3

Prostate cancer $(\mathrm{CaP})$ is the second most common malignancy prevalent in men worldwide, comprising $11.9 \%$ of all cancer cases diagnosed in 2002. There is considerable geographic variation in incidence, the disease being more common in the developed countries (19\%) than in developing countries (5.3\%) (Parkin et al, 2005). Even within the developed countries there is considerable variation in the rate of presentation, with the USA having the highest age-standardised incidence (124.8/100 000) and Japan the lowest $(12.6 / 100000)$. This is also reflected in the mortality rates, whereby North America, Northern and Western Europe have high age-standardised rates $(15.8,17.5$ and $19.7 / 100000$, respectively) as compared to Japan (5.7/100 000). Migrants from low- to high-risk countries show a marked increase in risk, reaching levels of cancer risk similar to that in resident populations (Haenszel, 1961; Haenszel and Kurihara, 1968). Although the aetiology and pathogenesis of $\mathrm{CaP}$ is unknown, various epidemiological studies have shown a relationship between dietary lipids and development of the disease (Snowdon et al, 1984; Giovannucci et al, 1993). Also there is increasing evidence that it is not only the quantity of lipid but the type of lipid intake that influences the risk of CaP. Omega6 poly-unsaturated fatty acids ( $\omega-6$ PUFA) have been shown to promote $\mathrm{CaP}$, whereas Omega $3(\omega-3)$ PUFA, from marine foods, may inhibit oncogenesis (Norrish et al, 1999).

*Correspondence: Dr MD Brown;

E-mail:mbrown@picr.man.ac.uk

Revised 20 January 2006; accepted 6 February 2006; published online 7 March 2006
Prostate cancer has a predilection to metastasise to the bone marrow stroma (BMS) of the axial skeleton. Men who develop $\mathrm{CaP}$ bone metastases will almost invariably die from their disease in the absence of an intercurrent illness, the median time between clinical presentation with bone metastases and death being 18 months (George, 1988). The mechanics of invasion through the endothelium into the BMS is a complex and multistep process, which is only just beginning to be understood with the utilisation of in vitro invasion chambers. These in vitro models allow not only the study of the mechanism of endothelial transmigration, but also the determination of specific BMS attractants. The exact nature of the stimulatory mechanisms which direct the PEC to the BMS are currently unknown although some components have been identified. The CXCR4/SDF-1 signalling pathway is a potent stimulator of PEC invasion (Taichman et al, 2002; Sun et al, 2003). However, in comparison to human BMS, it forms only a small part of the overall stimulus (Hart et al, 2005). The BMS is a lipid-laden environment, rich in various lipids including the $\omega-6$ PUFA's, linoleic acid (LA) $(4.1 \pm 0.84 \%$ to $15.3 \pm 2.9 \%)$ and arachidonic acid (AA) $(2.5 \pm 0.9$ to $9.52 \pm 0.4 \%$ ) (Sumida, 1965; Denizot et al, 1998; Denizot et al, 1999).

Studies of prostate epithelia have demonstrated the importance of lipid/cellular interactions. Mamalakis et al (2002) showed that relative to benign disease patients, the adipose tissue and prostatic tissue of $\mathrm{CaP}$ patients had reduced levels of AA and the $\omega-3$ lipid docosahexaenoic acid (DHA), and a reduced $\omega-3: \omega-6$ PUFA ratio. Adipocyte/epithelial cell interactions have been shown to induce proliferation of prostate (Tokuda et al, 2003) and mammary 
(Rahimi et al, 1994) cancer cell lines and plays an important role in normal breast development (Zangani et al, 1999).

Omega-6 PUFA's, especially the LA metabolite AA, has been associated with prostate cancer progression (Honn et al, 1994; Norrish et al, 1999), stimulating proliferation and inhibiting apoptosis (Ghosh, 2004). These effects are mediated by the increase in the cyclooxygenase-2 (COX-2) product prostaglandin $\mathrm{E}_{2}$ (PGE2) (Hughes-Fulford et al, 2005), and lipoxygenase (LOX) products 5 and 12(S)-HETE (hydroxyeicosatetraenoic acid). 5hydroxyeicosatetraenoic acid has been shown to induce PC-3 proliferation (O'Flaherty et al, 2002) and loss of 5-LOX expression in both DU145 and PC-3, by activation of the orphan nuclear receptor $\operatorname{ROR} \alpha$, has been shown to inhibit the proliferative effects of both AA and LA (Moretti et al, 2004). 12(S)-hydroxyeicosatetraenoic acid, does not induce PC-3 proliferation but induces endothelial invasion (angiogenesis) leading to increased proliferation in vivo (Nie et al, 1998).

The stimulatory ability of AA can be blocked by the addition of the $\omega$-3 PUFAs, eicosapentaenoic acid (EPA) and DHA. This may be due to $\omega-3$ PUFA modifying the AA biosynthetically derived prostaglandins and eicosanoids via competitive inhibition of the COX and LOX pathways (Karmali et al, 1987). Rose (1997) showed using malignant breast and PEC that both EPA and DHA not only blocked AA synthesis from LA by competition for $\Delta 4$ desaturase but also blocked prostaglandin and HETE synthesis from AA by direct competition for COX and LOX enzymes.

Epidemiological data suggest that the dietary ratio of $\omega-3: \omega-6$ PUFA is crucial in determining the risk of metastatic CaP. Here we present for the first time in vitro data showing that AA is a key attractant of metastatic PECs to human BMS and that this stimulus can be blocked in a PGE2-dependent manner by the addition of $\omega$-3 PUFAs.

\section{MATERIALS AND METHODS}

\section{Materials}

All Reagents were purchased from Sigma-Aldridge (Poole, UK) except AA, 5-HETE and 12(S)-HETE, which were supplied by MP Biochemicals UK (London, UK). All fatty acids were made up to $10 \mathrm{mg} \mathrm{ml}^{-1}$ in ethanol. All tissue culture medium and horse serum was from Invitrogen (Paisley, UK) with the exception of foetal calf serum (FCS) supplied by Labtech International Ltd (Uckfield, East Sussex, UK). Tissue culture plastic, Matrigel ${ }^{\circledR}$ Basement Membrane Matrix and $8 \mu \mathrm{m}$ cell culture inserts were from Becton Dickinson Labware (NJ, USA). Iwaki quartz-based $35 \mathrm{~mm}$ Petri dishes were supplied by Bibby Sterilin (Staffordshire, UK). Oil Red O was obtained from VWR International Ltd (Leicestershire, UK). The inhibitors NS-398 was from Alexis Corp and MirrIR slides from Keveley Technologies (Ohio, USA).

\section{Antibodies}

Mouse anti-human pan cytokeratin, Nile Red and DAB tablets were from Sigma-Aldridge (Poole, UK); rabbit anti mouse biotinylated antibody from DAKO Ltd (Cambridge, UK) and Vectastain Elite ABC kit from Vector Laboratories (CA, USA).

\section{Cell culture}

The PC-3 cell line (Kaighn et al, 1979) was cultured in Ham's F12 (Sigma) and $7 \%$ FCS and grown at $37^{\circ} \mathrm{C}$ in a humidified atmosphere of $5 \% \mathrm{CO}_{2}$ in air. Bone marrow stroma was cultured from human ribs removed for access during routine renal surgery after informed consent (ProMPT LREC 02/ST/122) and prepared for tissue culture using the method of (Coutinho et al, 1993). The cultures were grown at $33^{\circ} \mathrm{C}$ in $5 \% \mathrm{CO}_{2}$ in air for $4-5$ weeks until haemopoietically active areas were observed.

\section{Co-culture experiments}

Bone marrow stroma cultures were trypsinised and re-seeded into Iwaki quartz-based $35 \mathrm{~mm}$ Petri dishes at the same cell density and left to re-establish for 14 days. Bone marrow stroma media was replaced with medium containing $500 \mathrm{PC}-3$ cells/dish. The cocultures were incubated for $48 \mathrm{~h}$ at $37^{\circ} \mathrm{C}$ then fixed in $4 \%$ paraformaldehyde.

\section{Immunocytochemistry}

After fixation co-cultures were permeabilsed using ice-cold methanol, blocked with $10 \%$ rabbit serum followed by $0.3 \%$ hydrogen peroxide. Co-cultures were incubated with mouse antihuman pan cytokeratin at 1:200 followed by biotinylated rabbit anti-mouse 1:400. A complex of avidin $\mathrm{DH}$ and biotinylated horseradish peroxidase $\mathrm{H}$ was then added and developed with DAB substrate. Adipocytes were stained by Oil Red O. Briefly, cultures were rinsed in $60 \%$ isopropanol then incubated in a $0.5 \%$ Oil Red $\mathrm{O}$ in $60 \%$ isopropanol solution for $10 \mathrm{~min}$. Cultures were differentiated for a few minutes in fresh $60 \%$ isopropanol then rinsed with water.

\section{Brightfield volumetric analysis}

PC-3 and adipoctye cells stained with Oil Red O were analysed in colour. Planes of focus were visualised utilising a Zeiss AxioVert $35 \mathrm{M}$ with a C-Apochromat $\times 631.2 \mathrm{NA}$ water immersion objective lens under brightfield illumination. A stepper motor (Ludl electronics, NY, USA) was attached which permits fine control of the focus ( 0.2 micron steps). Images were then accumulated into a stack utilising Image J Image Analysis software (Rasband, 2005). A depth of focus algorithm was applied to each colour component of the volume, in greyscale, and the volume subsequently merged to form a colour volume of data. The image was then viewed in Imaris (Bitplane) and a cross sectional view of the data generated.

\section{Fourier transform infrared microscopy}

Prostate bone metastases paraffin-embedded sections, isolated from consenting patients, were mounted on MirrIR slides and deparaffinised with Citroclear followed by $20 \mathrm{~min}$ acetone treatment before air drying. High-definition FTIR microspectroscopic maps of $6.25 \mu \mathrm{m}$ pixel resolution of bone marrow tissue was collected in rapid-scan mode using a Perkin Elmer Spotlight spectrometer and a $16 \times 1$ MCT linear array detector. Mid-IR spectra within the wavenumber range $4000-748 \mathrm{~cm}^{-1}$ were collected in reflection mode. The background scan was recorded at $8 \mathrm{~cm}^{-1}$ spectral resolution with 75 scans, whereas the sample scan was recorded at $8 \mathrm{~cm}^{-1}$ spectral resolution with 60 scans. Fourier transform infrared microscopy spectral images were processed with Spotlight version 1.0.1.

\section{Invasion assay}

PC-3 invasion was assessed using the method described by Hart et al (2005). Briefly, Matrigel-coated cell culture inserts were placed in a 24 -well plate containing $1 \mathrm{ml}$ of DMEM/0.1\% fatty acidfree BSA with either plain tissue culture plastic (TCP-negative control), BMS (positive control) or escalating concentrations of AA, DHA, EPA, 5-HETE, 12(S)-HETE, 15(S)-HETE and Prostaglandin $\mathrm{E}_{2}$ (PGE2). The COX-2 inhibitor NS-398 was added at $8 \mu \mathrm{M}$. PC-3 cells, serum starved for $24 \mathrm{~h}$ in RPMI 1640 medium, were seeded at $1 \times 10^{5}$ per insert then incubated at $37^{\circ} \mathrm{C}$ for $18 \mathrm{~h}$ after which inserts were fixed and stained in $2 \%$ crystal violet and counted according to manufacturer's instructions using a grid graticule. 


\section{Uptake of AA in PC-3 cells using flow cytometry}

PC-3 cells were serum starved for $24 \mathrm{~h}$ in RPMI 1640 medium, trypsinised and placed in RPMI serum-free medium plus or minus $\mathrm{AA}$ at $10 \mu \mathrm{M}$ at a concentration of $2 \times 10^{5} \mathrm{cells} / \mathrm{ml}$. The cells were incubated in these conditions at $37^{\circ} \mathrm{C}$ in $5 \% \mathrm{CO}_{2}$ in air for up to $180 \mathrm{~min}$ before fixing and staining with $5 \mu \mathrm{M}$ Nile Red for $5 \mathrm{~min}$. Analysis was carried out using a FACS Vantage SE equipped with an argon ion laser running at $200 \mathrm{~mW} 488 \mathrm{~nm}$. Emission in the $560-565 \mathrm{~nm}$ range yellow/gold was measured using linear amplification. All cells were analysed within $30 \mathrm{~min}$.

\section{AA Uptake by PC-3 cells visualized using spinning disc confocal microscopy}

PC-3 cells were plated onto quartz-bottomed $35 \mathrm{~mm}$ petri dishes and grown to semi confluence. Cells were then serum starved in RPMI 1640 medium for $24 \mathrm{~h}$ before use. Before visualisation on the microscope, the media was exchanged for RPMI serum-free media (without phenol red) and $5 \mu \mathrm{M}$ Nile Red. Cells were visualised on a PerkinElmer Ultraview situated on a Zeiss Axiovert $200 \mathrm{M}$ with a full environmental chamber and heated objective set at $37^{\circ} \mathrm{C}$. Nile Red was excited using the $488 \mathrm{~nm}$ laser and the cells photographed every $5 \mathrm{~min}$ for $2 \mathrm{~h}$ in the $z$-axis and combined to give a continuous sequence.

\section{Statistics}

All values are presented as mean \pm s.e.m. All assays were compared by use of the two-tailed Student's $t$-test. A threshold of significance was set at $P<0.05$.

\section{RESULTS}

\section{Localisation of malignant PEC to BMS adipocytes and lipid uptake}

Tokuda et al (2003) showed that human PECs interact with adipocytes in vitro with a resultant increase in proliferation and differentiation of the PECs. We therefore analysed human prostate bone metastases chemometrically using Fourier transform infrared microscopy (FTIR), to determine whether PECs associate with lipid-rich regions within the BMS in vivo. Figure 1 shows serial sections of a human prostate bone metastasis stained with haematoxylin and eosin or examined chemometrically by FTIR. The spectral maps show the localisations of protein and lipid signals within the tissue, with blue representing the lowest signal and red the highest. The intensity distribution of the lipid hydrocarbon signal (using the $v$-band region between 3007 and $2978 \mathrm{~cm}^{-1}$ ) demonstrates a strong lipid signal associated with/ around the prostate bone metastasis suggesting either lipid uptake by the PECs or an association with lipid-rich regions within the BMS. It has also been observed in our previous studies of PECs cocultured in human long-term bone marrow cultures (Lang et al, 1997; Lang et al, 1998; Scott et al, 2000; Hart et al, 2002; Hart et al, 2005) malignant human PECs formed colonies in close proximity to adipocytes (unpublished finding).

We therefore hypothesised that malignant PECs may migrate towards adipocytes and utilise the lipids that they contained. To test this hypothesis, the PEC line PC-3 was seeded on to confluent long-term human BMS (Figure 2A-D) or primary prostate stroma (Figure 2E and F). PC-3 cells and lipid droplets were then visualised by staining with anti pan-cytokeratin, developed with $\mathrm{DAB}$, and Oil Red $\mathrm{O}$, respectively. Figure $2 \mathrm{~A}$ and $\mathrm{B}$ illustrates that PC-3 cells migrate towards and form colonies around lipid-rich areas. High-resolution brightfield microscopy of PC-3 cells surrounding/in close proximity to lipid droplets shows that PC-3 cells take up lipids from the surrounding area of BMS (Figure $2 \mathrm{C}$ and D). This observation was confirmed using brightfield volumetric analysis of the PC-3/BMS co-culture. Figure 2D shows a de-convolved image of a PC-3 cell dual stained with anti pancytokeratin and Oil Red $\mathrm{O}$ with $\mathrm{Z}$ plane data collected at $0.2 \mu \mathrm{M}$ steps. Along both the $x$ and $y$ axis are orthogonal planes of data bisecting a lipid droplet, confirming its location within the PC-3 cell.

Within the prostate stroma, which lacks lipid centres, the PC-3 cells do not congregate, appear as isolated cells within the stroma and do not have Oil Red O-stained lipid droplets within the cytoplasm (Figure 2E and F).

\section{Uptake of AA by PC-3 cells in vitro}

Hughes-Fulford et al (2005) showed that in the presence of an albumin carrier, uptake of AA by PC-3 cells could be detected after $2.5 \mathrm{~h}$. To determine the rate of lipid uptake from their environment in the absence of carrier, we conducted a series of monoculture experiments with $10 \mu \mathrm{M}$ albumin-free AA. Figure 3A I and II show adipocytes and PC-3 cells in the presence of AA, stained with $5 \mu \mathrm{M}$ Nile Red and visualised by fluorescent microscopy. The adipocytes are densely packed with yellow-staining lipid droplets. These are also observed in the PC-3 cells, although at a much lower frequency. This observation was confirmed by confocal imaging (Figure 3A III), and the internalisation and localisation of the lipid droplets was verified by 3D confocal microscopy (Figure 3A IV). Utilisation of a fluorescent lipid stain enabled the uptake of AA by PC-3 cells to be monitored over time (Figure 3B). PC-3 cells were incubated with $10 \mu \mathrm{m} \mathrm{AA}$, fixed and stained with $5 \mu \mathrm{m}$ Nile Red at different time points. The number of cells and the amount of AA taken up by the PC-3 cells was determined by flow cytometry and followed in real time by spinning disc fluorescent microscopy. Arachidonic acid is rapidly taken up by PC-3 cells with a maximal number of cells, $67.71 \pm 4.72 \%$, taking up AA at $30 \mathrm{~min}$. After this time there is a steady decline in the number of AA positively stained cells, with only $30.73 \pm 1.73 \%$ of PC- 3 cells staining positive $90 \mathrm{~min}$ post dosing. Maximum uptake occurs at $45 \mathrm{~min}$, with a geometric mean difference to the controls of $62.83 \pm 16.39$ $(P=0.019)$, a figure which again declines with time. This phenomenon was also confirmed in real time with time lapse spinning disc microscopy (Supplementary Figure 1).

\section{Effect of $\omega-3$ and $\omega-6$ PUFAs on invasion}

Omega-6 PUFAs, in particular AA, have been associated with an increase in risk of advanced $\mathrm{CaP}$ and that this risk can be reduced by increased intake of $\omega-3$ PUFAs. Therefore, we sought to determine the ability of AA, DHA and EPA to stimulate PC-3 invasion through a synthetic basement membrane, Matrigel, and to compare its ability to stimulate migration with human BMS.

PC-3 cells were cultured overnight in the presence of escalating doses of AA, DHA or EPA and cell viability assessed by Trypan blue exclusion. Only $100 \mu \mathrm{M}$ DHA was shown (Figure 4A) to have an effect on the overall cell viability of the PC-3 culture after $18 \mathrm{~h}$ exposure, reducing viability to $88.56 \pm 5.4 \%$ (although this did not reach statistical significance $(P=0.168))$.

To determine the ability of $\omega-3$ and $\omega-6$ PUFA to induce PEC invasion, exponentially growing PC-3 cells were seeded on to Matrigel-coated cell culture inserts above either TCP, human BMS or escalating doses $(5-100 \mu \mathrm{M})$ of AA, DHA or EPA. After $18 \mathrm{~h}$ at $37^{\circ} \mathrm{C}$ with $5 \% \mathrm{CO}_{2}$, the number of invasive cells was counted. Arachidonic acid at concentrations $\leqslant 50 \mu \mathrm{M}$, was shown to be a potent stimulus for invasion (Figure 4B), with concentrations of $\geqslant 5 \mu \mathrm{M}$ inducing similar levels of invasion to BMS $(5 \mu \mathrm{M} \mathrm{AA}$; $P=0.17)$. Arachidonic acid did not induce LnCaP or PNT2-C2 cell lines to invade even in the presence of androgen (Supplementary Figure 2). 
H\&E

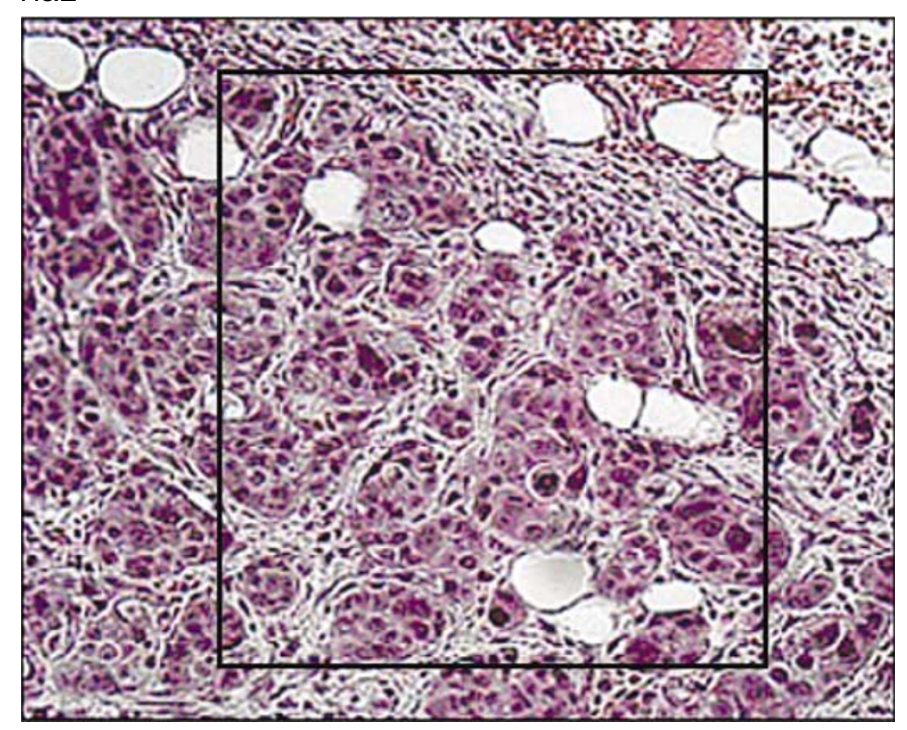

Brightfield

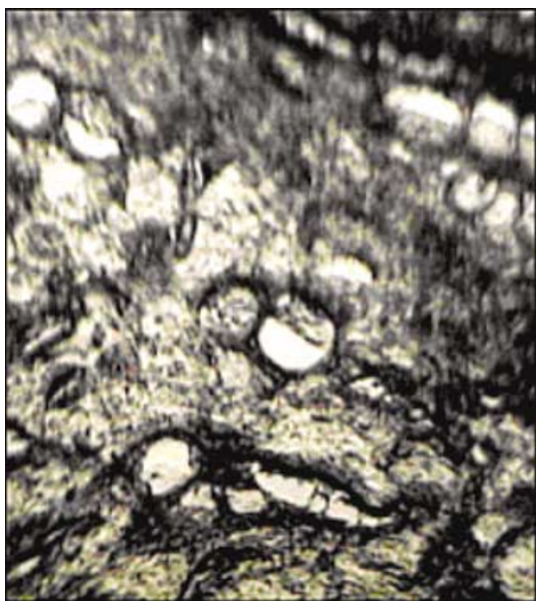

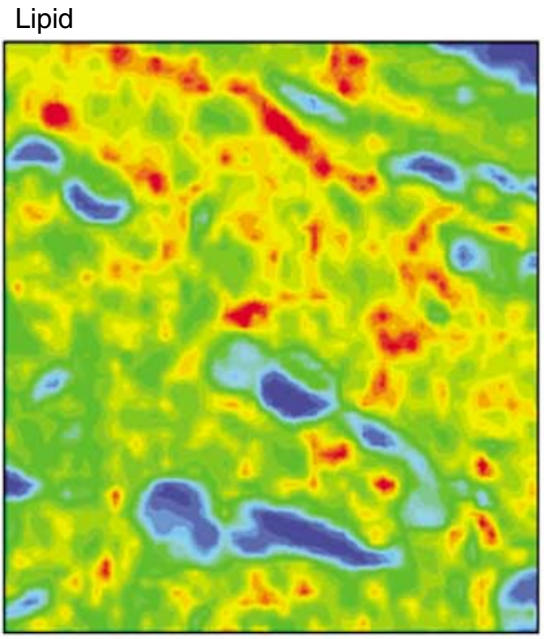

$100 \mu \mathrm{M}$
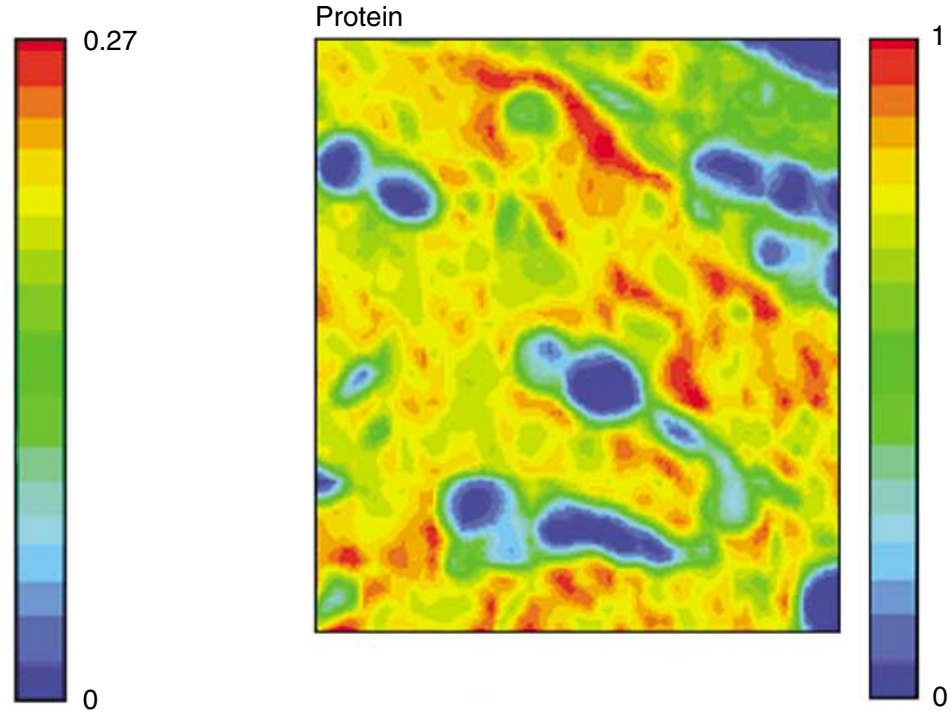

Figure I PECs localise to lipid-rich regions in bone marrow metastases. Fourier transform infrared microscopy chemometric analysis of prostate bone metastasis. Haematoxylin and eosin-stained section (H\&E) depicting bone metastasis. Square outlines the region of a serial section analysed by FTIR as shown by the brightfield image. The lighter shaded locations within the brightfield photomicrograph depict CaP cells. The lipid hydrocarbon peak area $\left(3007 \mathrm{~cm}^{-1}\right.$ to $\left.2798 \mathrm{~cm}^{-1}\right)$ intensity image displays lipid localisation within the section. The protein image $\left(1729 \mathrm{~cm}^{-1}\right.$ to $\left.\mid 485 \mathrm{~cm}^{-1}\right)$ reveals the boundary between the CaP cells and haemopoietic bone marrow. Scale bar $=100 \mu \mathrm{m}$.

In comparison, both EPA and DHA (Figure 4C and D) did not significantly induce invasion above the background level of TCP $(P \geqslant 0.05)$, except for $10 \mu \mathrm{M} \mathrm{EPA}$, which induced a small but nonsignificant increase in invasion of PC-3 cells $(418.5 \pm 45.2 v s$ $380.3 \pm 39.6 ; P=0.347)$. Eicosapentaenoic acid concentrations $\geqslant 50 \mu \mathrm{M}$ induced a reduction in the number of invading PC-3 cells in comparison to TCP $(325.9 \pm 35.2$ and $283 \pm 21.6 v s$ $380.3 \pm 39.6$ at $50 \mu \mathrm{M}$ and $100 \mu \mathrm{M}$, respectively) although these decreases were not significant $(P=0.576$ and $P=0.144$, respectively). With DHA at a $5 \mu \mathrm{M}$ concentration a nonsignificant reduction in cellular invasion was observed $(260.8 \pm 33.8 v s$ $380.3 \pm 39.6 ; P=0.098$ ) by comparison with TCP.

\section{$\omega$-3 inhibits $\omega$-6-stimulated PEC invasion}

The proliferative potential of AA has been shown to be abrogated by the addition of $\omega$-3 PUFA's (Honn et al, 1994; Rose, 1997;
Norrish et al, 1999). We sought to determine whether the addition of $\omega$-3 PUFAs to an environment rich in AA would reduce the level of induced invasion. Figures $5 \mathrm{~A}$ and $\mathrm{B}$ shows the effect of the addition of increasing concentrations of EPA or DHA to an invasion chamber containing $10 \mu \mathrm{M}$ of $\mathrm{AA}$ as a stimulus and compared to TCP and BMS.

Both EPA and DHA were potent blockers of AA stimulation of invasion. Eicosapentaenoic acid and DHA, at concentrations $\geqslant 5 \mu \mathrm{M}$ completely inhibited invasion towards $10 \mu \mathrm{M} \mathrm{AA}$, inducing similar levels of invasion as TCP $(776.8 \pm 74.1$ vs $858.7 \pm 55.1$; $P=0.396$ and $723.7 \pm 68.1$ vs $858.7 \pm 55.1 ; P=0.154$ by comparison with TCP for $5 \mu \mathrm{M}$ EPA and DHA, respectively).

\section{PGE2 recovers $\omega-6$ induced invasion in the presence of $\omega-3$}

To determine the basic mechanism of $\omega-3$ inhibition of AAinduced malignant PEC invasion, we repeated the invasion assays 

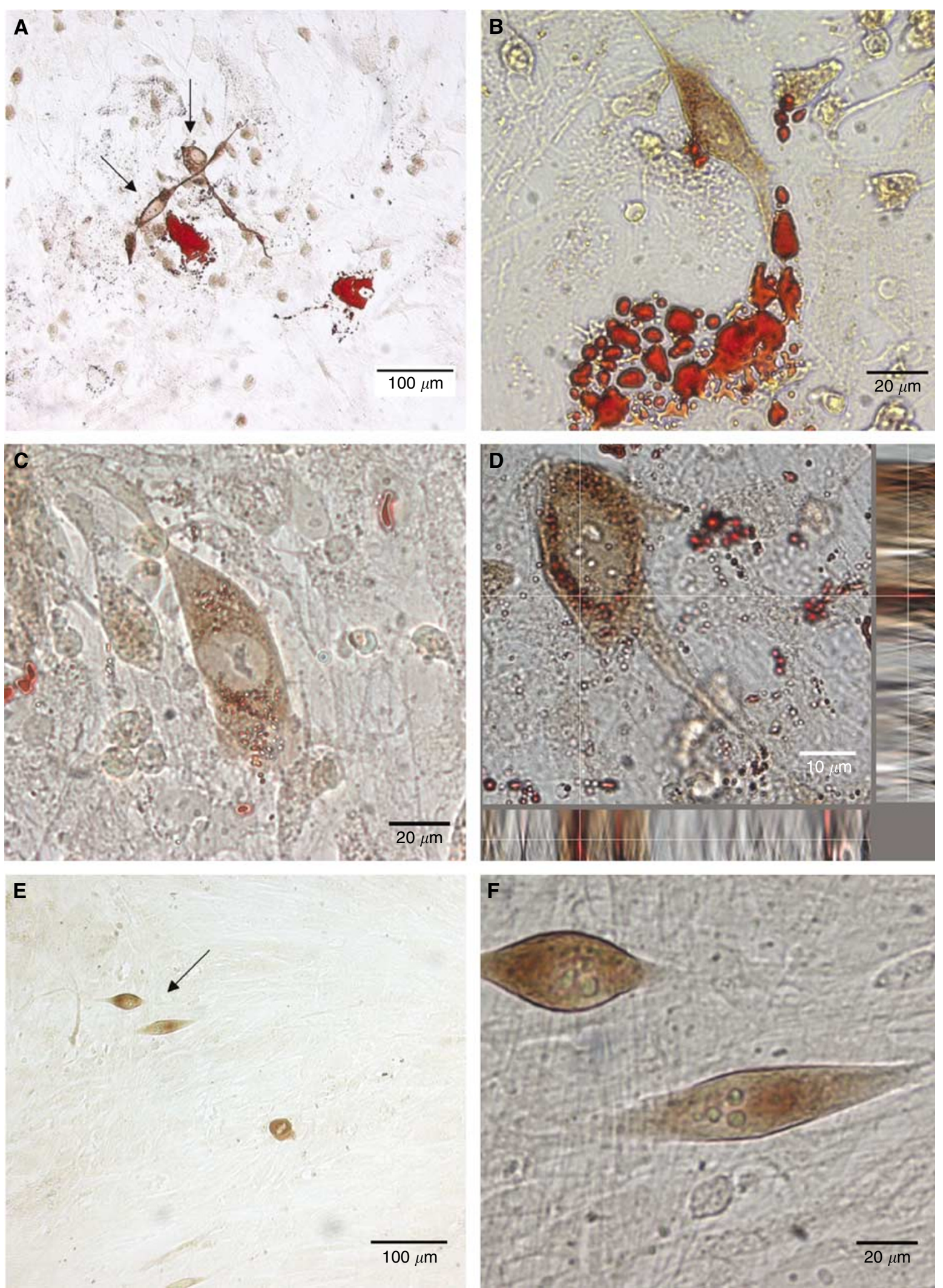

Figure 2 PC-3 cells localise to adipocytes in BMS co-culture and take up lipids. $5 \times 10^{2}$ PC-3 cells co-cultured with primary long-term human BMS, visualised by staining with anti pan-cytokeratin and developed by DAB (brown). Bone marrow adipocytes and lipid droplets were visualised by staining with $0.5 \%$ Oil Red O. Images were captured utilising a Zeiss AxioVert $35 \mathrm{M}$ with a C-Aprochromat $\times 63 \quad 1.2 \mathrm{NA}$ water immersion objective lens. (A-C) Brightfield photomicrographs of PC-3 cells co-cultured with BMS showing PC-3 localisation to bone marrow adipocytes and lipid uptake. (D) Deconvolved brightfield image showing localisation of lipid droplets within the PC-3 cytoplasm. $x$ and $y$ panels show orthogonal planes of data along the white cross hair. (E-F) Brightfield photomicrograph of PC-3 cells co-cultured with primary human prostate fibroblasts. 
A

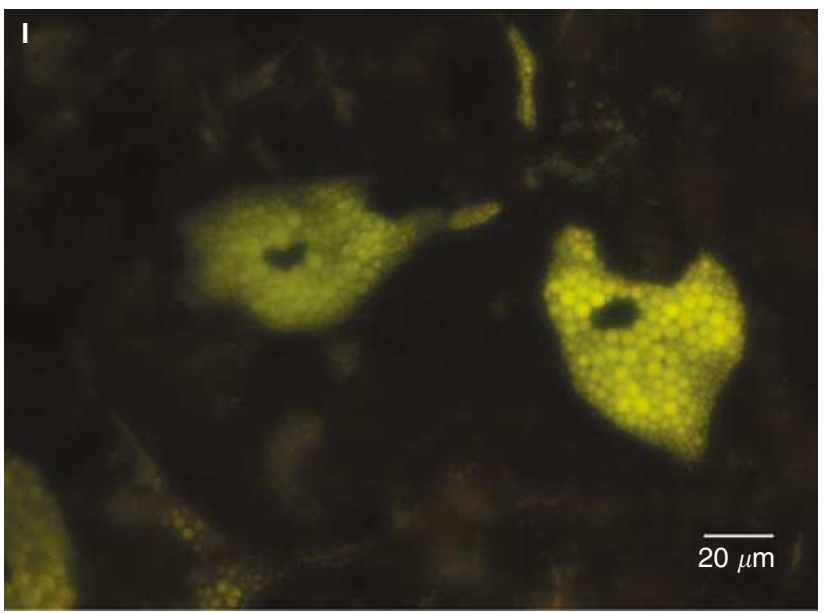

III

$10 \mu \mathrm{m}$

B

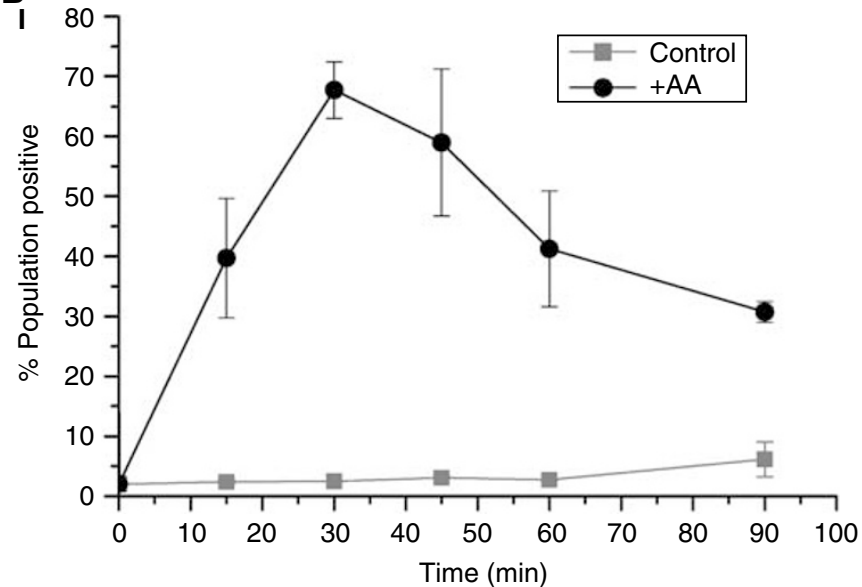

II

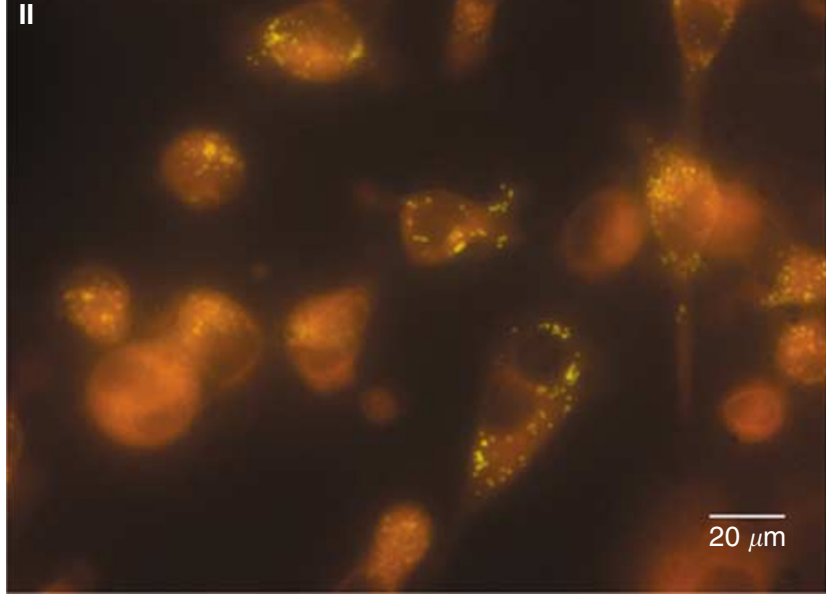

IV

$10 \mu \mathrm{m}$

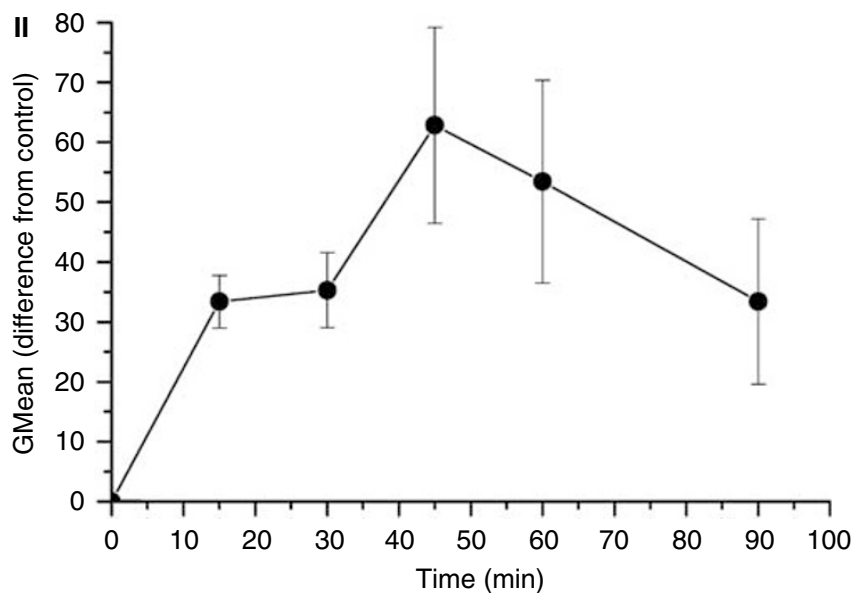

Figure 3 PC-3 cells rapidly take up the $\omega$-6 PUFA AA from the microenvironment. (A) The lipid content of (I) bone marrow adipocytes or (II) PC-3 cell after loading with AA was visualised by fluorescent yellow/gold Nile Red staining (488 nm excitation-565 nm emission). (III) High-resolution confocal false coloured image of AA pulsed PC-3 cells. (IV) Confocal 3D relief image showing localisation of lipid droplets within the cytoplasm of PC-3 cells. (B) FACS analysis following the uptake of AA by serum-starved PC-3 cells over time after Nile Red staining; (I) graph depicting the percentage of the population staining positive for AA uptake overtime, (II) graph showing the level of AA uptake by PC-3 cells overtime as determined by the geometric fluorescent mean.

with $10 \mu \mathrm{M}$ AA blocked with $20 \mu \mathrm{M} \omega-3$ PUFA and attempted recovery of invasion by the addition of the AA metabolites, 5HETE, 12(S)-HETE, 15(S)-HETE and PGE2. All AA metabolites were titrated for their ability to stimulate invasion of PC-3 cells through a Matrigel basement membrane and used in subsequent experiments at the optimum concentration (data not shown).

Figure $6 \mathrm{~A}-\mathrm{C}$ show the effect of the addition of AA lipoxygenase products, 5-HETE, 12(S)-HETE and 15(S)-HETE on PC-3 invasion 

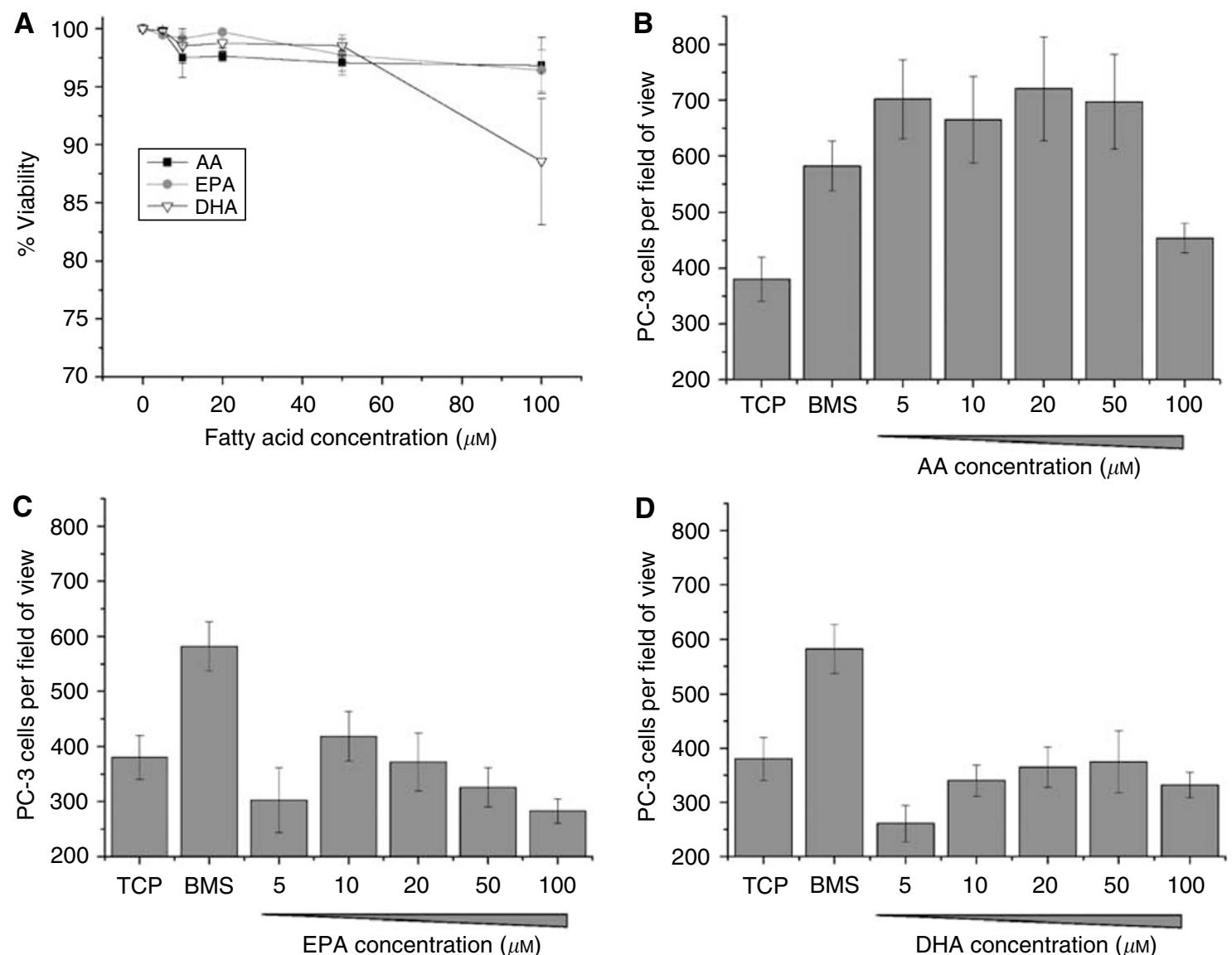

Figure 4 Omega-3 and $\omega-6$ PUFAs do not reduce PC-3 cell viability but only AA induces cellular invasion. (A) Graph showing the effect of escalating doses of AA, DHA or EPA on PC-3 cell viability $18 \mathrm{~h}$ post dosing as determined by trypan blue exclusion $(n=2)$. (B) Histograms showing the stimulatory effect of increasing concentrations of AA, (C) EPA and (D) DHA on the number of PC-3 invading through Matrigel over $18 \mathrm{~h}$. Data represents mean number of cells per field of view plus standard error bars generated from four independent experiments $(n=4)$.

towards $10 \mu \mathrm{M} \mathrm{AA}$ in the presence of blocking concentrations of DHA or EPA $(20 \mu \mathrm{M})$. Although 5-HETE (Figure 6A) did not induce invasion in its own right $(748.7 \pm 43.3 v s 719.6 \pm 43.4$ (5-HETE $v s$ TCP), $P=0.64$ ), addition of $100 \mathrm{nM} 5$-HETE to AA blocked with $20 \mu \mathrm{M}$ EPA induced significant recovery of PC-3 invasion $(931.3 \pm 68.4$ vs $719.6 \pm 43.4 ; P=0.00457)$ as compared to EPA control. Although addition of $100 \mathrm{~nm}$ 5-HETE to AA blocked with $20 \mu \mathrm{M}$ DHA induced PC-3 invasion as compared to the DHA control, it was not significant $(844 \pm 52.4$ vs $719 \pm 43.4 ; P=0.1425)$.

15(S)-hydroxyeicosatetraenoic acid (Figure 6B) induced invasion of PC-3 cells as compared to TCP $(769 \pm 38.7$ vs $641.8 \pm 29.8$; $P=0.016)$ and partially restored PC-3 invasion in the presence of EPA-blocked AA $(803.3 \pm 67.6$ vs $584.5 \pm 44.6, \quad P=0.0222$ by comparison with the EPA blocked AA control). However, addition of 15(S)-HETE did not release the DHA blocked system $(P=0.4887$ as compared to DHA control). 12(S)-hydroxyeicosatetraenoic acid like 15(S)-HETE (Figure 6C) induced invasion of PC-3 by itself, inducing 802.6 \pm 30.4 vs $691 \pm 38.6$ cells to invade $(P=0.0333$ in comparison to TCP). Like 5-HETE and 15(S)-HETE, 12(S)-HETE was only able to release the invasive block induced by EPA, resulting in $935.9 \pm 49.6$ vs $774.8 \pm 40.3$ cells invading $(P=0.01944)$ as compared to EPA control.

Prostaglandin $\mathrm{E}_{2}$ was shown to be a potent stimulator of PC-3 invasion, with $10 \mathrm{ng} \mathrm{ml}^{-1}$ inducing similar levels to AA $(915.42 \pm 64.5$ vs $997.8 \pm 55.5 ; P=0.3431)$. Addition of $10 \mathrm{ng} \mathrm{ml}^{-1}$ PGE2 to an invasion blocked system, with $10 \mu \mathrm{M} \mathrm{AA}$ acting as the main stimulus and $20 \mu \mathrm{m}$ of either EPA, DHA or $8 \mu \mathrm{M}$ NS-398 blocking invasion (Figure 6D), resulted in complete recovery of
AA-induced invasion $(997.8 \pm 55.47 v s \quad 1022.8 \pm 84.7(P=0.8042)$, $911.8 \pm 46 \quad(P=0.2452), \quad 974.3 \pm 14 \quad(P=0.6841) \quad$ for $\mathrm{AA} \quad v s$ $\mathrm{EPA}+\mathrm{PGE} 2, \mathrm{DHA}+\mathrm{PGE} 2$ and NS-398 + PGE2, respectively).

\section{Only EPA inhibits invasion towards BMS}

To determine the potential of $\omega-3$ inhibition of malignant PEC invasion towards human BMS, in vitro co-culture assays were set up utilising human BMS as the target for invasion in the presence of escalating concentrations of either EPA or DHA (Figure 7A and $B)$. Eicosapentaenoic acid at concentrations $\geqslant 20 \mu \mathrm{M}$ reduced invasion toward BMS $(655.8 \pm 55.8(P=0.04085)$ and $535.3 \pm 44$ $(P=0.0003)$ vs $796.2 \pm 21.4$ at 20 and $50 \mu \mathrm{M}$, respectively) as compared to BMS. However, this was not observed with DHA at concentrations up to $100 \mu \mathrm{M}(P=0.2905$ as compared to BMS).

\section{AA recovers invasive ability of depleted BMS}

To address the potential role of AA in the stimulation of invasion towards BMS in vivo, in vitro co-culture invasion models were constructed using long-term human BMS grown in the presence or absence of hydrocortisone, essential for the formation of adipocytes in the BMS (Toogood et al, 1980) and hence haemopoiesis (Dexter et al, 1977). We utilised these cultures as a source of lipid-free BMS. Figure 7C shows photomicrographs of 5 -week-old human BMS cultures from the same donor grown in the presence or absence of $0.5 \mu \mathrm{M}$ hydrocortisone. Both cultures developed similar confluent BMS fibroblasts. However, in the 


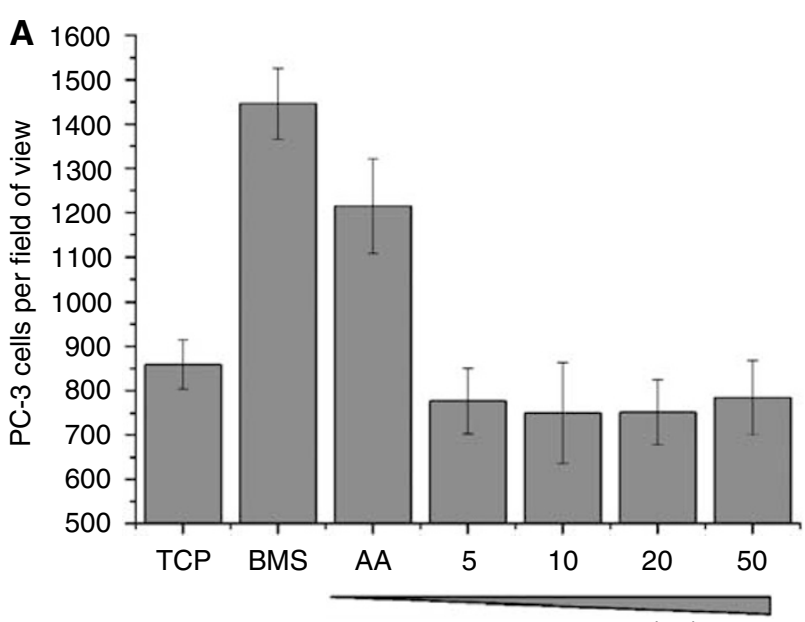

EPA concentration $(\mu \mathrm{M})$

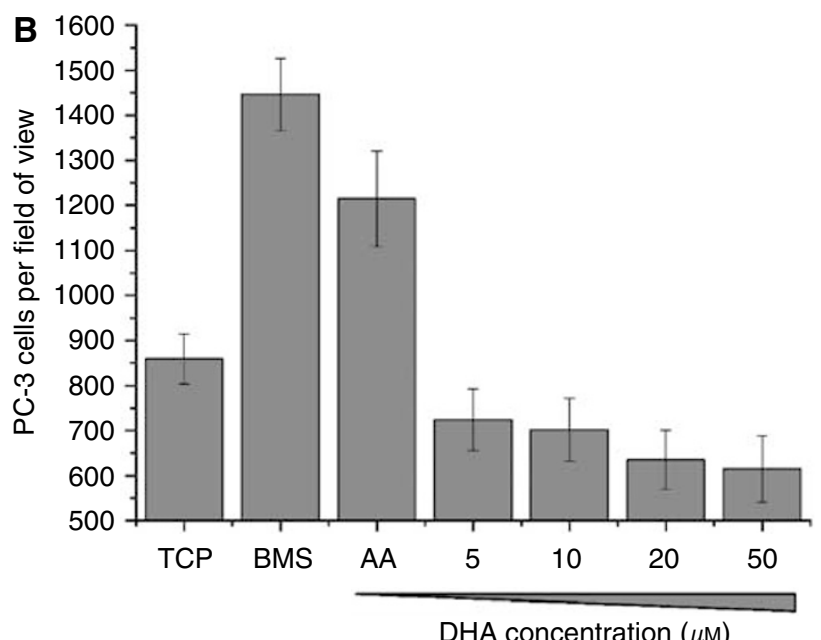

Figure 5 Addition of $\omega$-3 PUFAs inhibits $\omega$-6-induced PC-3 invasion. Histograms showing the effect of increasing concentrations of (A) EPA or (B) DHA on PC-3 invasion through Matrigel over $18 \mathrm{~h}$ towards $10 \mu \mathrm{M}$ AA. Data represents mean number of cells per field of view plus standard error bars generated from three independent experiments $(n=3)$.

absence of hydrocortisone there were no signs of haemopoiesis or colonies of adipocytes.

The ability of the hydrocortisone-depleted BMS to act as a stimulant for invasion was then assessed in comparison to normal BMS and the ability of AA to recover invasion was determined (Figure 7D). Hydrocortisone-depleted BMS weakly stimulated PC-3 invasion through Matrigel (838.6 \pm 59.6 vs $688.5 \pm 61.1$; $P=0.1096$ as compared to TCP) but was a significantly weaker stimulus than control BMS $(P=0.0059)$. Addition of $10 \mu \mathrm{m} \mathrm{AA}$ to the hydrocortisone-depleted BMS restored the ability of this BMS to induce invasion, with measured levels of invasion comparable to the level induced by normal BMS also supplemented with $10 \mu \mathrm{M}$ AA $(1280 \pm 43 v s 1308 \pm 42.9 ; P=0.655)$.

\section{DISCUSSION}

The role of diet, especially PUFAs, in CaP has been a highly controversial subject with epidemiological studies generating conflicting information as to the effect of $\omega-6$ and $\omega-3$ PUFAs in the pathogenesis and progression of $\mathrm{CaP}$. In vitro studies examining the role of both families of PUFAs in $\mathrm{CaP}$ have provided some insight into the potential mechanisms of their effect. Metabolism of the essential $\omega-6$ PUFA LA leads to the production of AA, metabolites of which have been shown, in the case of 5(S)-HETE, to protect PEC from apoptosis and to induce proliferation, and in the case of 12(S)-HETE to induce endothelial invasion and angiogenesis in vivo, leading to the formation of larger tumours. These effects have been shown to be abrogated by the use of $\omega$-3 PUFAs (Rose and Connolly, 1999). In this study we have addressed for the first time the role of PUFAs in stimulating BMS metastatic migration, because of the known predilection that prostate cancer has for the haemopoietic bone marrow. This study is the first to demonstrate that $\omega$-3 PUFAs have an inhibitory effect on cell migration in vitro and thus potentially metastasis.

The means by which cancer cells migrate in a site-specific manner, and in particular, the reasons underlying the predilection that some cancers such as prostate cancer have for the red bone marrow are poorly understood. There are a number of potential factors which may be influential but presently, there is no specific known mechanism. The CXCR4/SDF-1 axis has been postulated as being critical in this process (Taichman et al, 2002; Sun et al, 2003) but we have previously shown that this forms only a part of the invasive stimulus generated by the BMS (Hart et al, 2005). The BMS is a lipid-rich environment, with the presence of adipocytes being of critical importance for the haemopoietic process (Dexter et al, 1977). Lipid-related studies of the BMS microenvironment have shown that the lipid component comprises of various fats including oleic acid $(35.2 \pm 4.9 \%)$, palmitic acid $(27.8 \pm 2.5)$, palmitoleic $(8.1 \pm 2.7 \%)$ stearic acid $(6.3 \pm 1.4 \%)$ and linoleic acid $(12.3 \pm 2.7-15.3 \pm 2.9 \%)$ (Sumida, 1965; Denizot et al, 1999). Arachidonic acid, a metabolite of LA, is also present within the BMS although the concentration varies from $2.5 \pm 0.9 \%$ in the BMS plasma to $9.52 \pm 0.4 \%$ within the cellular component (Denizot et al, 1998). As the body ages the amount of fatty tissue/yellow bone marrow increases (up to $10 \%$ every decade (Compston, 2002)), along with a notable increase in adipocytes (Meunier et al, 1971; Rozman et al, 1989). Using our co-culture in vitro models of BMS invasion, we have shown that the bone metastatic CaP cell line PC3 actively seek out and move towards adipocyte-rich regions of the BMS. In the presence of bone marrow adipocytes the PC-3 cells were observed to take up lipids actively and in a time-dependent manner (Figures $1-3$ ). The role of lipid uptake is currently unclear but it is possible that the lipid may be utilised as an energy substrate to meet the needs of the accelerated cellular metabolism, known to be a feature of the metastasising malignant cell, and indeed it has been shown that prostate cancer cells interact with adipocytes. Tokuda et al (2003) showed that PC-3/adipocytes cocultures induced both $\mathrm{PC}-3$ proliferation and differentiation. Conversion of LA to AA leads to the generation of AA metabolites, PGE2, 5-HETE, 12(S)-HETE and 15(S)-HETE. Both PGE2 and 5HETE have been shown to have CaP proliferative properties. Studies by Hughes-Fulford et al (2005) demonstrated that $\leqslant 10 \mu \mathrm{M}$ AA induced PC-3 proliferation by elevating expression of cPLA2 and COX-2, fivefold and threefold respectively, with subsequent increased levels of PGE2. 12(S)-hydroxyeicosatetraenoic acid also increased prostate tumour growth by increasing angiogenesis with subsequent decrease in necrosis, but it has also been shown to have varied roles in the metastatic processes in $\mathrm{CaP}$, including enhancing cell motility (Honn et al, 1994; Gao et al, 1995). Unlike PGE2, 5-HETE and 12(S)-HETE, 15(S)-HETE is associated with benign prostate tissue. Formation of 15(S)-HETE is reduced in the majority of $\mathrm{CaP}$ (Shappell et al, 1999) and it acts as a PPAR $\gamma$ agonist (Shappell et al, 2001), an effect which has been shown to inhibit proliferation of breast (Mueller et al, 1998), colon (Brockman et al, 1998) and bladder (Brockman et al, 1998) carcinoma cell lines.

As a major component of the lipid composition of normal BMS adipocytes is LA and its metabolite AA (Sumida, 1965; Denizot et al, 1998; Denizot et al, 1999) and that the level of AA decreases 


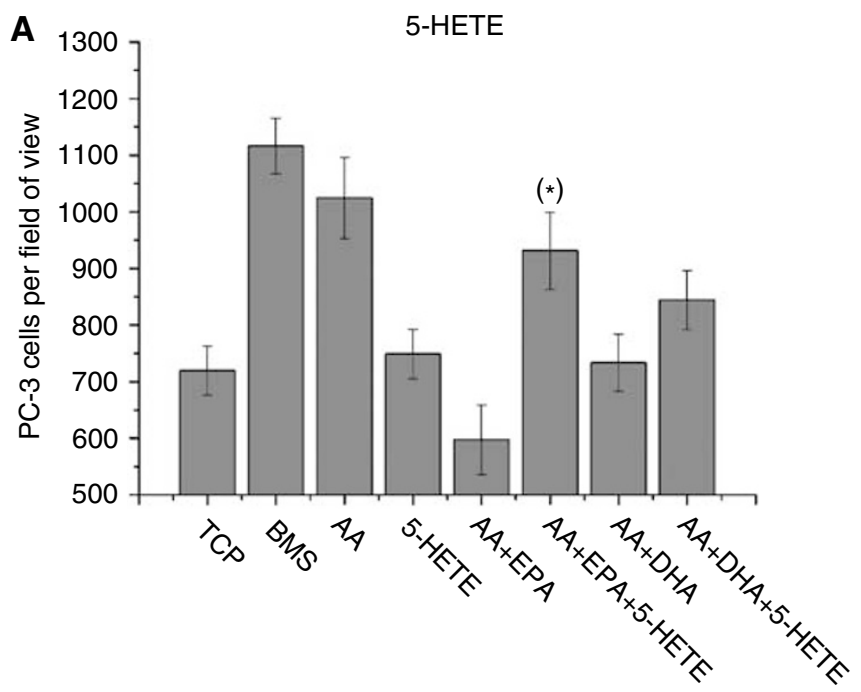

B 1300
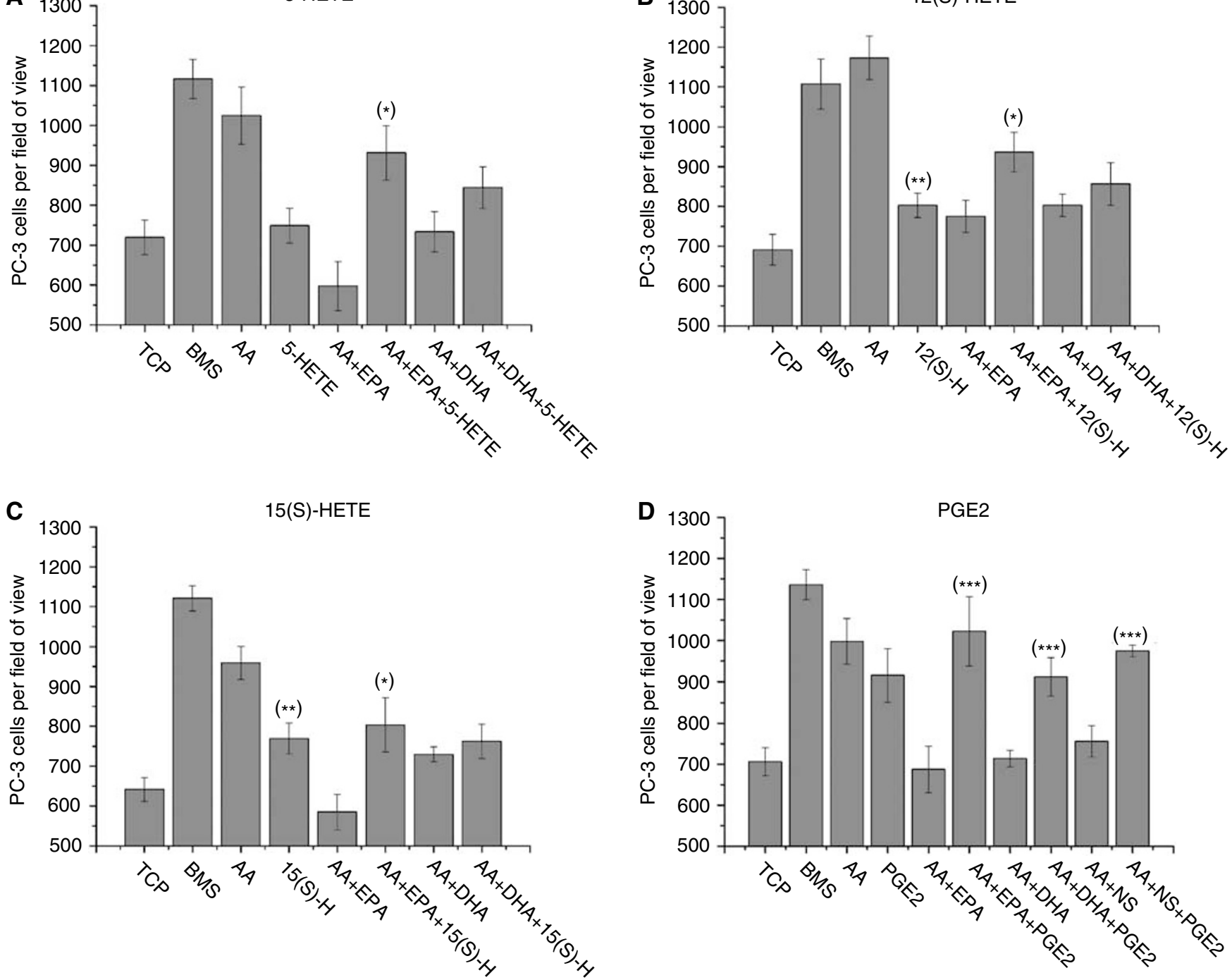

Figure 6 Inhibition of AA-induced invasion by DHA and EPA is via the blockade of prostaglandin $E_{2}$ synthesis. Histograms showing the effect of the $A A$ metabolites, 5-HETE (I00 nM), I2(S)-HETE (300 nM), I5(S)-HETE (I $\mu \mathrm{M})$ or PGE2 (I $0 \mathrm{ng} / \mathrm{ml})$, on restoring PC-3 cell invasion through Matrigel towards AA $(10 \mu \mathrm{M})$ following blockade by the addition of either $20 \mu \mathrm{M}$ EPA, DHA or the COX-2 inhibitor NS398. Data represents mean number of cells per field of view plus standard error bars generated from six independent experiments $(n=6)$. * $=P$ value $\leqslant 0.05$ as compared to $\omega-3$ control; *** $=P$ value $\leqslant 0.05$ as compared to TCP control; $* * * *=P$ value $\geqslant 0.05$ as compared to AA

in the prostate cancer patients (Mamalakis et al, 2002), we sought to determine the rate of lipid uptake. PC-3 cells cultured in the presence of $10 \mu \mathrm{M} \mathrm{AA}$ and stained with Nile Red rapidly took up the PUFA from the local environment (within $15 \mathrm{~min}$ ), reaching a maximum level of uptake after $45 \mathrm{~min}$. The level of AA then diminished over time suggesting metabolism of the AA into PGE2 (Hughes-Fulford et al, 2005) or HETEs. This potential rapid metabolism of AA, correlating with patient data (Mamalakis et al, 2002; Faas et al, 2003), suggests that AA cyclooxgenase and lipoxygenase products are potentially important components of the cancer process.

The study by (Mamalakis et al, 2002) also showed that despite a reduction of $\mathrm{AA}$ in prostatic tissues between $\mathrm{CaP}$ and $\mathrm{BPH}$ patients there was no significant difference in the levels of AA within the adipose tissue. We therefore hypothesised that the level of AA within the adipocyte-rich BMS may be maintained in $\mathrm{CaP}$ patients and act as an attractant for metastatic PEC. Using our in house in vitro invasion assays we showed that AA was a potent stimulator of invasion, inducing similar levels of invasion as to those seen using
BMS. This series of experiments showed that AA is a far stronger stimulator of invasion than SDF-1 (Hart et al, 2005) and that this is possibly the predominant signal for invasion of the BMS, leading to the characteristic disturbance of the skeletal and bone marrow metabolism.

The importance of the AA signal from the BMS was further confirmed in our in vitro co-culture models utilising primary human BMS cultures grown in the presence or absence of hydrocortisone (Figure 7C and D). Toogood et al (1980) showed that mesenchymal progenitors within the BMS cultured in the absence of hydrocortisone do not differentiate into adipocytes. In the absence of adipocytes, BMS induced PC-3 invasion but at a significantly lower level than adipocyte-rich BMS. The small amount of invasion observed was possibly due to the production of other factors such as SDF-1, which has previously been shown to induce PC-3 invasion, by the BMS (Hart et al, 2005). Addition of $10 \mu \mathrm{M}$ AA completely restored the ability of adipocyte-free BMS to induce PC-3 invasion demonstrating the potency of AA to induce invasion. 

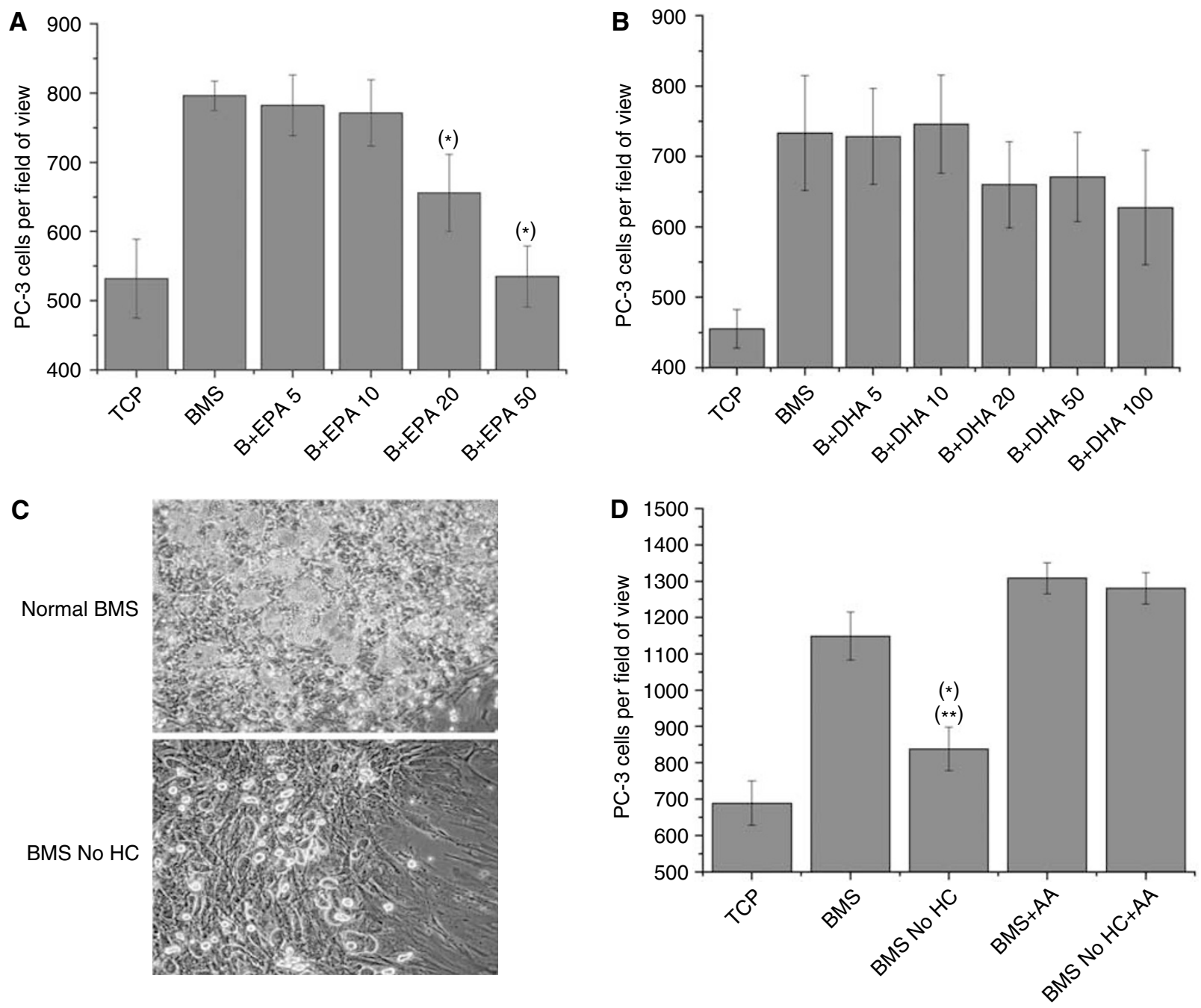

Figure 7 PC-3 cell invasion towards BMS is dependent on bone marrow adipocytes and $\omega-6$ metabolism. (A) PC-3 cell invasion towards BMS in the presence of escalating doses $(5-50 \mu \mathrm{M})$ of EPA. (B) PC-3 cell invasion towards BMS in the presence of escalating doses (5- I00 $\mu \mathrm{M})$ of DHA. Data represents mean number of cells per field of view plus standard error bars generated from three independent experiments $(n=3)$. (C) Photomicrographs of a 5-week-old human bone marrow culture, grown in the presence of $0.5 \mu \mathrm{M}$ hydrocortisone, showing the presence of haemopoietic centres and adipocytes, or in the absence of hydrocortisone, showing stromal development and the absence of adipocytes. (D) PC-3 cell invasion towards BMS, grown in the presence or absence of $0.5 \mu \mathrm{M}$ hydrocortisone (No HC), with or without $10 \mu \mathrm{M}$ AA. Data represents mean number of cells per field of view plus standard error bars generated from three independent experiments $(n=3)$. * $=P$ value $\leqslant 0.05$ as compared to BMS; ** $=P$ value $\leqslant 0.05$ as compared to TCP.

Omega-3 PUFAs, especially the marine PUFAs, EPA and DHA, have been shown to inhibit the proliferation of both prostate and breast cancer cells in vitro and in vivo. The mode of action of $\omega-3$ PUFAs is by competing with AA for the cyclooxygenases and the lipoxygenases, leading to the production of metabolically inactive products such as $\Delta^{17}-6$-keto-PGF and $\mathrm{TXB}_{3}$ (reviewed in Rose and Connolly, 1999). Furthermore, dietary intake of $\omega$-3 PUFAs has been associated with a decreased risk in developing aggressive/ metastatic CaP (Terry et al, 2001; Augustsson et al, 2003). Epidemiological evidence now points to the importance of the $\omega-3: \omega-6$ ratio within the diet and a decrease in this ratio is associated with increased risk of aggressive disease (Rose and Connolly, 1999). This is most noticeable in the diets of Japanese and Eskimos who traditionally had a high $\omega-3: \omega-6$ ratio due to high fish intake. This has changed over the last couple of decades to a more Western low $\omega-3: \omega-6$ diet with a subsequent increase in the risk of both breast (Wynder et al, 1991) and prostate cancer (Lanier et al, 1976; Lanier et al, 1996).
Here we demonstrate that the $\omega$-3 PUFAs DHA and EPA are strong inhibitors of invasion towards AA capable of blocking invasion at a ratio of $1: 2 \omega-3: \omega-6$ (Figure 5). The predominant block is in the production of PGE2 by COX-2 as the addition of $10 \mathrm{ng} \mathrm{ml}^{-1}$ PGE2 to an $\omega-3$ or NS-398 COX-2 inhibitor blocked system restores the level of PC-3 invasion (Figure 6D). Therapeutic blockade of PGE2 production using COX inhibitors such as NSAIDs or specific COX-2 inhibitors such as celecoxib, rofecoxib and NS-398 have shown potential to inhibit both tumour growth and metastasis in experimental animal models (Dandekar and Lokeshwar, 2004; Patel et al, 2005). However, there are concerns after observations that COX-2 inhibitors increase the risk of cardiovascular events during both the VIGOR and APC trials (reviewed in Krotz et al, 2005; Luo et al, 2005). Unlike the synthetic COX-2 inhibitors, EPA and DHA are associated with a reduced risk of cardiovascular disease and sudden cardiac death (Holub and Holub, 2004; Harrison and Abhyankar, 2005). Trials have shown that the early administration of $1 \mathrm{~g} \mathrm{day}^{-1} \omega-3$ PUFA supplements 
reduced the risk of sudden cardiac death by $45 \%$ and the overall mortality by $20 \%$ (Marchioli et al, 2002) and that doses of up to $4 \mathrm{~g} \mathrm{day}^{-1}$ doses can be tolerated (reviewed in Harrison and Abhyankar, 2005). Therefore we propose that there is particular scope for the use of dietary DHA and EPA not only to effect proliferation but also in the anti-metastatic treatment of $\mathrm{CaP}$.

The data suggests that both DHA and EPA may also act on different pathways involved in invasion. Figure 5 shows that both $5 \mu \mathrm{M}$ DHA and EPA reduced PC-3 invasion to levels similar to that of nondirectedmigration but the addition of the lipoxygenase products 5, 12(S) and 15(S)-HETE show different patterns of recovery (Figure 6). Addition of HETEs was able to partially restore the invasive effect of $\mathrm{AA}$ in the presence of EPA but did not remove the DHA block. Surprisingly 15(S)-HETE, which is not produced from AA by PC-3 owing to loss of 15-LOX-2 expression and plays a role in the suppression of $\omega$-6-induced PEC proliferation (Shappell et al, 1999; Shappell et al, 2001), partially restored EPA-blocked PC-3 invasion. However, addition of PGE2 to systems blocked by either EPA or DHA completely restored invasion towards either AA or BMS. This difference was highlighted by the potential of $\omega-3$ PUFAs to inhibit PC-3 invasion towards primary BMS cultures (Figure 7A and B). Only EPA was able to block invasion towards BMS although only at higher concentrations $(20-50 \mu \mathrm{M})$ than observed in the monoculture invasion assays. This may be due to the presence of PGE2 and HETEs already within the co-culture which is due to the metabolism of $\omega-6$ PUFAs by cells within the BMS. Within this system, however, DHA was unable to block the BMS invasive stimuli, even at a final concentration of $100 \mu \mathrm{M}$.

In summary we have provided in vitro evidence supporting the epidemiological data that the dietary ratio of $\omega-3: \omega-6$ is crucial in determining the risk of metastatic disease in $\mathrm{CaP}$. Arachidonic acid is a potent stimulator of PEC invasion and is a major component of the stimulus directing metastatic PEC to the BMS to form bone metastases. As the epidemiological data suggests, increasing the ratio of $\omega-3: \omega-6$ PUFAs, in particular increasing the amount of EPA in the diet, can inhibit the metastatic process by blocking the production of PGE2 and therefore reducing the risk of aggressive disease.

\section{ACKNOWLEDGEMENTS}

This work was supported by the AICR grant 04-518 and the MRC Northern ProMPT collaborative. We thank Gary Ashton and Caron Abbey, Department of Histology, CR-UK Paterson Institute for the Oil Red O staining of PC-3 BMS/prostate fibroblast co-cultures and Jeff Barry and Mike Hughes, Cytometry Facility, CR-UK Paterson Institute for FACS analysis.

Supplementary Information accompanies the paper on British Journal of Cancer website (http://www.nature.com/bjc)

\section{REFERENCES}

Augustsson K, Michaud DS, Rimm EB, Leitzmann MF, Stampfer MJ, Willett WC, Giovannucci E (2003) A prospective study of intake of fish and marine fatty acids and prostate cancer. Cancer Epidemiol Biomarkers Prev 12: $64-67$

Brockman JA, Gupta RA, Dubois RN (1998) Activation of PPARgamma leads to inhibition of anchorage-independent growth of human colorectal cancer cells. Gastroenterology 115: 1049-1055

Compston JE (2002) Bone marrow and bone: a functional unit. J Endocrinol 173: $387-394$

Coutinho LH, Gilleece MH, de Wynter E, Will A, Testa NG (1993) Clonal and long-term cultures using human bone marrow. In Haemopoiesis: A Practical Approach Testa NGMG (ed), pp 75-106. Oxford: Oxford University Press

Dandekar DS, Lokeshwar BL (2004) Inhibition of cyclooxygenase (COX)-2 expression by Tet-inducible COX-2 antisense cDNA in hormonerefractory prostate cancer significantly slows tumor growth and improves efficacy of chemotherapeutic drugs. Clin Cancer Res 10: $8037-8047$

Denizot Y, Desplat V, Dulery C, Trimoreau F, Praloran V (1999) Arachidonic acid and freshly isolated human bone marrow mononuclear cells. Mediators Inflamm 8: $31-35$

Denizot Y, Dulery C, Trimoreau F, Desplat V, Praloran V (1998) Arachidonic acid and human bone marrow stromal cells. Biochim Biophys Acta 1402: 209-215

Dexter TM, Allen TD, Lajtha LG (1977) Conditions controlling the proliferation of haemopoietic stem cells in vitro. J Cell Physiol 91: $335-344$

Faas FH, Dang AQ, White J, Schaefer RF, Johnson DE (2003) Decreased prostatic arachidonic acid in human prostatic carcinoma. BJU Int 92: $551-554$

Gao X, Grignon DJ, Chbihi T, Zacharek A, Chen YQ, Sakr W, Porter AT, Crissman JD, Pontes JE, Powell IJ, Honn KV (1995) Elevated 12 lipoxygenase mRNA expression correlates with advanced stage and poor differentiation of human prostate cancer. Urology 46: $227-237$

George NJ (1988) Natural history of localised prostatic cancer managed by conservative therapy alone. Lancet 1: 494-497

Ghosh J (2004) Rapid induction of apoptosis in prostate cancer cells by selenium: reversal by metabolites of arachidonate 5-lipoxygenase. Biochem Biophys Res Commun 315: 624-635
Giovannucci E, Rimm EB, Colditz GA, Stampfer MJ, Ascherio A, Chute CC Willett WC (1993) A prospective study of dietary fat and risk of prostate cancer. J Natl Cancer Inst 85: $1571-1579$

Haenszel W (1961) Cancer mortality among the foreign-born in the United States. J Natl Cancer Inst 26: $37-132$

Haenszel W, Kurihara M (1968) Studies of Japanese migrants. I. Mortality from cancer and other diseases among Japanese in the United States. J Natl Cancer Inst 40: 43-68

Harrison N, Abhyankar B (2005) The mechanism of action of omega-3 fatty acids in secondary prevention post-myocardial infarction. Curr Med Res Opin 21: $95-100$

Hart CA, Brown M, Bagley S, Sharrard M, Clarke NW (2005) Invasive characteristics of human prostatic epithelial cells: understanding the metastatic process. Br J Cancer 92: 503-512

Hart CA, Scott LJ, Bagley S, Bryden AA, Clarke NW, Lang SH (2002) Role of proteolytic enzymes in human prostate bone metastasis formation: in vivo and in vitro studies. Br J Cancer 86: 1136-1142

Holub DJ, Holub BJ (2004) Omega-3 fatty acids from fish oils and cardiovascular disease. Mol Cell Biochem 263: 217-225

Honn KV, Tang DG, Gao X, Butovich IA, Liu B, Timar J, Hagmann W (1994) 12-lipoxygenases and 12(S)-HETE: role in cancer metastasis. Cancer Metastasis Rev 13: 365-396

Hughes-Fulford M, Tjandrawinata RR, Li CF, Sayyah S (2005) Arachidonic acid, an omega- 6 fatty acid, induces cytoplasmic phospholipase A2 in prostate carcinoma cells. Carcinogenesis 26: 1520-1526

Kaighn ME, Narayan KS, Ohnuki Y, Lechner JF, Jones LW (1979) Establishment and characterization of a human prostatic carcinoma cell line (PC-3). Invest Urol 17: 16-23

Karmali RA, Reichel P, Cohen LA, Terano T, Hirai A, Tamura Y, Yoshida S (1987) The effects of dietary omega-3 fatty acids on the DU-145 transplantable human prostatic tumor. Anticancer Res 7: 1173- 1179

Krotz F, Schiele TM, Klauss V, Sohn HY (2005) Selective COX-2 inhibitors and risk of myocardial infarction. J Vasc Res 42: $312-324$

Lang SH, Clarke NW, George NJ, Allen TD, Testa NG (1998) Interaction of prostate epithelial cells from benign and malignant tumor tissue with bone-marrow stroma. Prostate 34: 203-213

Lang SH, Clarke NW, George NJ, Testa NG (1997) Primary prostatic epithelial cell binding to human bone marrow stroma and the role of alpha2beta1 integrin. Clin Exp Metastasis 15: 218-227 
Lanier AP, Bender TR, Blot WJ, Fraumeni Jr JF, Hurlburt WB (1976) Cancer incidence in Alaska natives. Int J Cancer 18: 409-412

Lanier AP, Kelly JJ, Smith B, Harpster AP, Tanttila H, Amadon C, Beckworth D, Key C, Davidson AM (1996) Alaska Native cancer update: incidence rates 1989-1993. Cancer Epidemiol Biomarkers Prev 5: $749-751$

Luo C, He ML, Bohlin L (2005) Is COX-2 a perpetrator or a protector? Selective COX-2 inhibitors remain controversial. Acta Pharmacol Sin 26: 926-933

Mamalakis G, Kafatos A, Kalogeropoulos N, Andrikopoulos N, Daskalopulos G, Kranidis A (2002) Prostate cancer vs hyperplasia: relationships with prostatic and adipose tissue fatty acid composition. Prostaglandins Leukot Essent Fatty Acids 66: 467-477

Marchioli R, Barzi F, Bomba E, Chieffo C, Di Gregorio D, Di Mascio R, Franzosi MG, Geraci E, Levantesi G, Maggioni AP, Mantini L, Marfisi RM, Mastrogiuseppe G, Mininni N, Nicolosi GL, Santini M, Schweiger C, Tavazzi L, Tognoni G, Tucci C, Valagussa F (2002) Early protection against sudden death by $n-3$ polyunsaturated fatty acids after myocardial infarction: time-course analysis of the results of the Gruppo Italiano per lo Studio della Sopravvivenza nell'Infarto Miocardico (GISSI)-Prevenzione. Circulation 105: 1897-1903

Meunier P, Aaron J, Edouard C, Vignon G (1971) Osteoporosis and the replacement of cell populations of the marrow by adipose tissue. A quantitative study of 84 iliac bone biopsies. Clin Orthop Relat Res 80: $147-154$

Moretti RM, Montagnani Marelli M, Sala A, Motta M, Limonta P (2004) Activation of the orphan nuclear receptor RORalpha counteracts the proliferative effect of fatty acids on prostate cancer cells: crucial role of 5-lipoxygenase. Int J Cancer 112: 87-93

Mueller E, Sarraf P, Tontonoz P, Evans RM, Martin KJ, Zhang M, Fletcher C, Singer S, Spiegelman BM (1998) Terminal differentiation of human breast cancer through PPAR gamma. Mol Cell 1: $465-470$

Nie D, Hillman GG, Geddes T, Tang K, Pierson C, Grignon DJ, Honn KV (1998) Platelet-type 12-lipoxygenase in a human prostate carcinoma stimulates angiogenesis and tumor growth. Cancer Res 58: $4047-4051$

Norrish AE, Skeaff CM, Arribas GL, Sharpe SJ, Jackson RT (1999) Prostate cancer risk and consumption of fish oils: a dietary biomarker-based case-control study. Br J Cancer 81: 1238-1242

O'Flaherty JT, Rogers LC, Chadwell BA, Owen JS, Rao A, Cramer SD, Daniel LW (2002) 5(S)-Hydroxy-6,8,11,14-E,Z,Z,Z-eicosatetraenoate stimulates PC3 cell signaling and growth by a receptor-dependent mechanism. Cancer Res 62: 6817-6819

Parkin DM, Bray F, Ferlay J, Pisani P (2005) Global cancer statistics, 2002. CA Cancer J Clin 55: 74-108

Patel MI, Subbaramaiah K, Du B, Chang M, Yang P, Newman RA, CordonCardo C, Thaler HT, Dannenberg AJ (2005) Celecoxib inhibits prostate cancer growth: evidence of a cyclooxygenase-2-independent mechanism. Clin Cancer Res 11: 1999-2007
Rahimi N, Saulnier R, Nakamura T, Park M, Elliott B (1994) Role of hepatocyte growth factor in breast cancer: a novel mitogenic factor secreted by adipocytes. DNA Cell Biol 13: 1189-1197

Rasband W (2005) ImageJ. Bethesda, Maryland, USA: US National Institutes of Health

Rose DP (1997) Effects of dietary fatty acids on breast and prostate cancers: evidence from in vitro experiments and animal studies. Am J Clin Nutr 66: $1513 S-1522 S$

Rose DP, Connolly JM (1999) Omega-3 fatty acids as cancer chemopreventive agents. Pharmacol Ther 83: 217-244

Rozman C, Feliu E, Berga L, Reverter JC, Climent C, Ferran MJ (1989) Agerelated variations of fat tissue fraction in normal human bone marrow depend both on size and number of adipocytes: a stereological study. Exp Hematol 17: $34-37$

Scott LJ, Clarke NW, Sharrard MS, George NJ, Lang SH (2000) Invasive phenotype of primary human prostatic epithelial cells. Prostate Cancer Prostatic Dis 3: $1136-1142$

Shappell SB, Boeglin WE, Olson SJ, Kasper S, Brash AR (1999) 15lipoxygenase-2 (15-LOX-2) is expressed in benign prostatic epithelium and reduced in prostate adenocarcinoma. Am J Pathol 155: 235-245

Shappell SB, Gupta RA, Manning S, Whitehead R, Boeglin WE, Schneider C, Case T, Price J, Jack GS, Wheeler TM, Matusik RJ, Brash AR, Dubois RN (2001) 15S-Hydroxyeicosatetraenoic acid activates peroxisome proliferator-activated receptor gamma and inhibits proliferation in PC3 prostate carcinoma cells. Cancer Res 61: 497-503

Snowdon DA, Phillips RL, Choi W (1984) Diet, obesity, and risk of fatal prostate cancer. Am J Epidemiol 120: 244-250

Sumida T (1965) Clinical and experimental study on fatty acid composition of bone marrow lipid in hematologic disorders. Acta Med Nagasaki 9: $222-241$

Sun YX, Wang J, Shelburne CE, Lopatin DE, Chinnaiyan AM, Rubin MA, Pienta KJ, Taichman RS (2003) Expression of CXCR4 and CXCL12 (SDF1) in human prostate cancers (PCa) in vivo. J Cell Biochem 89: 462-473

Taichman RS, Cooper C, Keller ET, Pienta KJ, Taichman NS, McCauley LK (2002) Use of the stromal cell-derived factor-1/CXCR4 pathway in prostate cancer metastasis to bone. Cancer Res 62: 1832-1837

Terry P, Lichtenstein P, Feychting M, Ahlbom A, Wolk A (2001) Fatty fish consumption and risk of prostate cancer. Lancet 357: 1764-1766

Tokuda Y, Satoh Y, Fujiyama C, Toda S, Sugihara H, Masaki Z (2003) Prostate cancer cell growth is modulated by adipocyte-cancer cell interaction. BJU Int 91: 716-720

Toogood IR, Dexter TM, Allen TD, Suda T, Lajtha LG (1980) The development of a liquid culture system for the growth of human bone marrow. Leuk Res 4: 449-461

Wynder EL, Fujita Y, Harris RE, Hirayama T, Hiyama T (1991) Comparative epidemiology of cancer between the United States and Japan. A second look. Cancer 67: 746-763

Zangani D, Darcy KM, Shoemaker S, Ip MM (1999) Adipocyte-epithelial interactions regulate the in vitro development of normal mammary epithelial cells. Exp Cell Res 247: 399-409 